\title{
3D Print of the Maxillary Sinus for Morphological Study
}

\author{
Impresión 3D del Seno Maxilar para su Estudio Morfológico
}

\author{
Nadia Araneda ${ }^{1}$; Marcelo Parra ${ }^{2,3}$; José Valdivia Osorio ${ }^{4}$ \& Sergio Olate Se, $^{2,3}$
}

ARANEDA, N.; PARRA, M.; OSORIO, J. V. \& OLATE, S. 3D Print of the maxillary sinus for morphological study. Int. J. Morphol., 35(3):1102-1106, 2017.

SUMMARY: The maxillary sinus (MS) is described as a pyramid-shaped cavity of the maxilla. Knowledge of its morphology makes it possible to define normality and abnormality so that its three-dimensional analysis can be a valuable preoperative tool during surgery in this anatomical area. The aim of this study is to present a strategy of morphological analysis of the MS using 3D printing acquired through computed cone beam tomography (CBCT) images. A cross-sectional descriptive study was conducted, including 15 subjects ( 8 women and 7 men). The 3D virtual reconstruction and modeling was done on the MSs bilaterally, and 30 physical models were produced on a 3D printer. The results revealed that the MSs obtained exhibited various morphologies. An individual analysis of each MS allowed the tripod nature of the MS to be defined. We also were able to observe anatomical repairs such as the MS ostium, as well as complex areas affecting important surgical decisions. This method for creating 3D models of MSs provides a new approach to understanding the precise anatomical characteristics in these structures, which cannot be assessed in the same way on a 2D screen. It may be concluded that 3D printouts of the MS are a suitable method of preoperative analysis that can be useful in educating the patient, however, less time-consuming strategies should be explored.

KEY WORDS: Maxillary sinus; 3D printing; Biomodel.

\section{INTRODUCTION}

The maxillary sinus (MS) is described as a pyramidshaped cavity within the maxilla (Lawson et al., 2008; Misch et al., 2008). The volume of the human MS can vary depending on factors such as age, sex, state of dentition, and in a bilateral comparison in the same patient (Jun et al., 2005; Kirmeier et al., 2011; Amin \& Hassan, 2012; Saccucci et al., 2015). Studies on the MS growth and development in humans of different ages have been reported using cadaver skulls, x-rays, computed tomography (CT) and magnetic resonance (MR) (Jun et al.).

The drawback in analyzing skulls without information of sex and age, makes it difficult to reach conclusions. Furthermore, the absence of soft tissue in the skull limits the analysis of the impact of sinus mucosa on these measurements. Likewise, the use of x-rays can alter the real dimensions of the anatomical structures since a projection can cause divergences from the real condition with limited accuracy (Jun et al.).
Considering its complex anatomy MR and CT are the most suitable methods to study the MS, but their use is limited by the high doses of radiation, additional costs and accessibility (Raghav et al., 2014; Saccucci et al.). Nonetheless, some of these limitations have been controlled with the introduction of cone beam computed tomography (CBCT), which has a lower radiation dose than CT and is more cost effective than MR (Saccucci et al.). However, the 2D images present in studies with CT or CBCT do not provide enough information given the complex $3 \mathrm{D}$ anatomy of the MS (Saccucci et al.); therefore, the use of specific software which provides a volumetric reconstruction of the MS and a 3D printout, may be more efficient in this type of analysis.

CBCT allows the reconstruction of three-dimensional objects. Using specific algorithms for data postprocessing, a spatial model can be extracted from a set of images and then be exported to a processing system. That

\footnotetext{
${ }^{1}$ Programa de Magister en Odontología, Universidad de La Frontera, Temuco, Chile.

${ }^{2}$ Programa de Doctorado en Ciencias Morfologícas, Universidad de La Frontera, Temuco, Chile.

${ }^{3}$ División de Cirugía Oral y Maxilofacial \& CEMYQ, Universidad de La Frontera, Temuco, Chile.

${ }^{4}$ Programa de Especialización en Implantología Buco Maxilofacial, Universidad Autónoma de Chile, Temuco, Chile.
} 
spatial model of data is used by $3 \mathrm{D}$ printers to produce a prototype of the final model (Rengier et al., 2010).

Prototyping was defined in the 1980s to describe new technologies that could produce physical models directly and in a relatively short time from three-dimensional objects using systems for computer-aided design (CAD). Other terms have also been used in the past to describe this technology, including solid freeform fabrication, additive layer manufacturing, 3D printing and advanced digital manufacturing (Elgalal et al., 2009).

The aim of the present study is to present a strategy of morphological analysis of the MS using 3D printing.

\section{MATERIAL AND METHOD}

A cross-sectional descriptive analytical study was designed in the 3D Study Laboratory at the Research Center in Applied Morphology \& the Center for Morphological and Surgical Research (CEMYQ) Universidad de La Frontera, Temuco, Chile. Fifteen subjects were included, 8 women age 20 or older, and 7 men, age 30 or older, who presented complete maxillary and mandibular dentition (not including the third molars) and a CBCT indicating some type of dental treatment. Patients with injuries affecting the MS (tumors, odontogenic lesions, bone lesions, traumatic injuries, inflammatory lesions) or surgeries in the area, subjects with current or past orthodontic treatment and subjects undergoing endodontic therapy on a tooth associated with the maxillary sinus were excluded. CBCT studies that showed metallic devices on the image were also excluded. Two dentists were calibrated with 10 CBCT images to accurately recognize the limits of the MSs on the three axes (axial, coronal and sagittal) first using the Ez 3D 2009 program (Vatech, México D.F., Mexico) and then the Slicer 4.4 program (Slicer.org, USA, 2014). In all cases, the CBCT images were acquired on the Pax Zenith imaging system (Vatech, Korea, 2011), using $90 \mathrm{kV}$ and $120 \mathrm{~mA}$, FOV $24 \times 19 \mathrm{~cm}$. The images were exported as DICOM files and processed as virtual models. This study was approved by the Science Ethics Committee of the Universidad de La Frontera with Protocol $001 / 16$

Creation of virtual 3D models of MSs. The CBCT data were analyzed on a computer by importing the files in DICOM format to the Slicer 4.4 program, identifying the 2D images for the manual delimitation of the MS borders; this method was selected to increase the accuracy in the anatomical borders due to the inherent irregularity of the MS; thus, errors regarding its shape could be avoided. Image filling was done in each 2D section of the MS (coronal, sagittal and cross-sectional), eliminating the intrasinus septum and septa (Fig.1), using another tool from the computer program to generate a virtual 3D model of each MS based on the previously filled 2D sections in STL format.

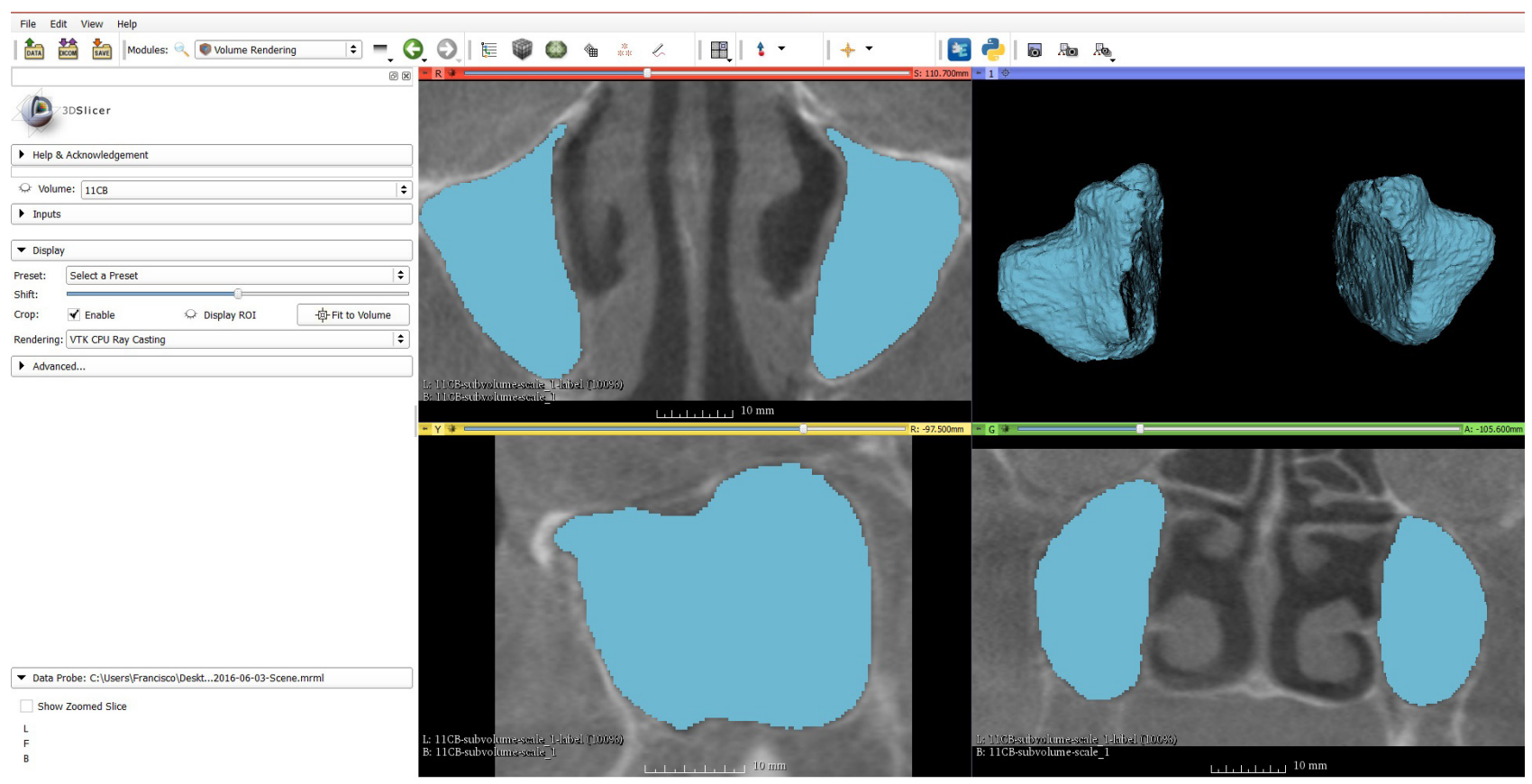

Fig. 1. Direct work on the software to determine the areas of the maxillary sinus in 2D images; the image segmentation obtains the image of the maxillary sinus in the different spatial directions. 
Creation of the physical 3D prototype of the MS. The 30 virtual models were exported to the 3D ReplicatorG design program (GNU, USA, 2012), where the MSs were positioned spatially and transferred to $\mathrm{x} 3 \mathrm{~g}$ format to be reconstructed physically on the Mbot Grid II 3D printer (Magicfirm MBot3D, China, 2014) using PLA (polylactic acid) material specific to this type of printer. Technical specifications are related to the 3D Printer, in this case, working with a medium quality using a resolution of $0.2 \mathrm{~mm}$ by layer. All the printed models were done on a 1:1 scale.

\section{RESULTS}

30 MSs were printed with no modifications to the originally established protocol. The time used in the process decreased from the first to the last, demonstrating the normal learning curve for this technology. The time used in the process from the initial modeling phase was approximately 300 min per MS and in the printing phase it was close to 25 min per MS.

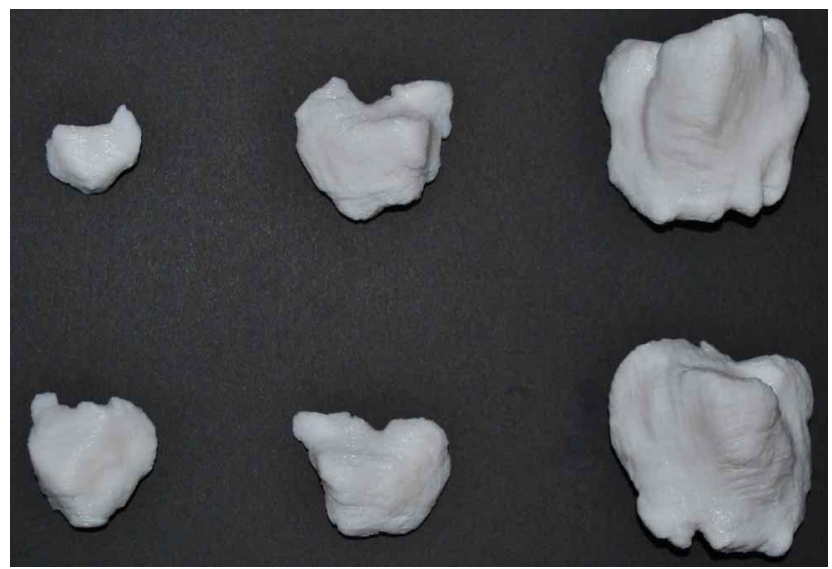

Fig. 2. The upper row presents the view of the side area of 3 maxillary sinus from 3 different subjects; in the lower row the side view of 3 left maxillary sinuses from the same subjects is shown.

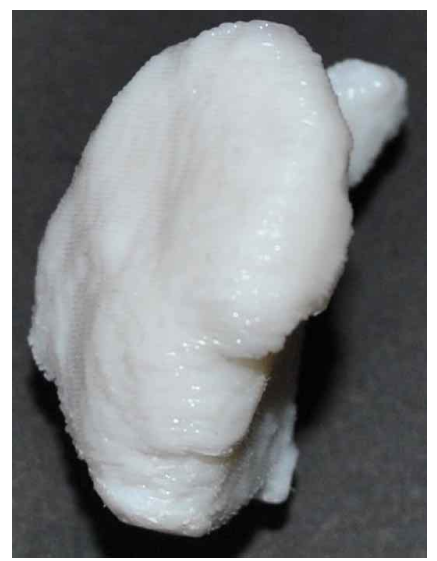

Fig. 3. Image of the medial zone of a right maxillary sinus
The MSs obtained provided various morphologies (Fig. 2), indicating the variability of shapes and sizes observed in these models. The individual analysis of each MS defined the tripod nature, observing the lower, side and medial areas (Fig. 3); anatomical repairs like the MS ostium and the complex zones in the surgical decisions could be seen, demonstrating the versatility of the physical reconstruction of the MS.

The relation between $3 \mathrm{D}$ printing and the $\mathrm{CBCT}$ image was confirmed (Fig. 4); the physical presence of the reconstructed MS provides direct visual information so as to define the shape and size of the MS, as well as the best method of approach. The sinus volume was not identified, but routine techniques can be used for this objective.

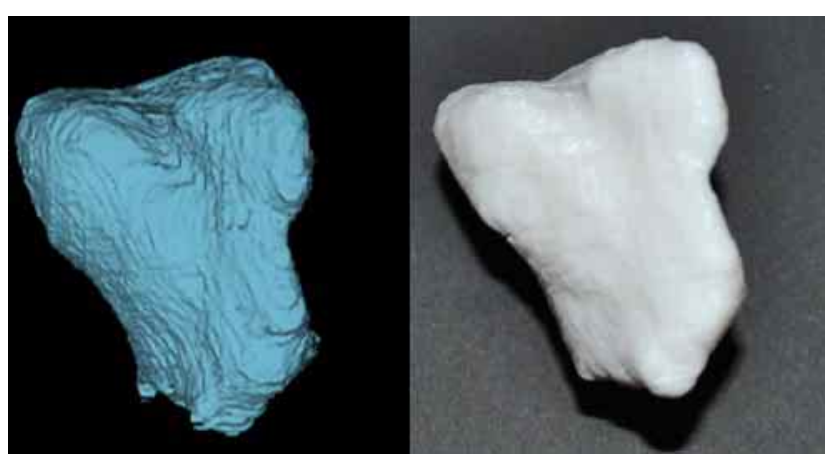

Fig. 4. Volume obtained on the software and its relation to the printed 3D prototype of the maxillary sinus.

\section{DISCUSSION}

The size and volume of the MSs vary in different skulls and even between the right and left sides of the same skull, it is essential to define the morphology and internal dimension of the MS as these impact the different types of treatment (Kirmeier et al.). Lawson et al. consider that the MSs have preserved their morphology without major alterations between multiethnic groups, but that the volume can vary in diverse populations. Other researchers suggest that the shape of the MS may be a response to the size and shape of the facial skeleton (Holton et al., 2013). Given the varied results found in the literature with respect to the MS morphology, the authors of this study note that it is an area with clear challenges in research, so that testing a new method for its evaluation represents a response to different questions.

The method for printing the MSs for subsequent analysis and morphological evaluation allows us to overcome the limitations of the 3D visualizations, which we can only 
analyze on a flat screen (Rengier et al.). In recent years, 3D printing has had medical applications in different areas like specialized planning through the simulation of the entire surgical sequence, using model prototypes, which gives a better appreciation of different anatomical details. This may result in a reduction in operating time and in an improvement of the use of resources in operating rooms (D'Urso et al., 1999; Wagner et al., 2004; Gerstle et al., 2014). On the other hand, 3D printouts are useful for educating the patient, or during the pre- or post-operative stage (Gerstle et al.).

This technique also has prosthetic applications (Rengier et al.; Matsumoto et al., 2014; Vidal \& Vidal, 2014), improving and facilitating the quality of diagnosis, since the use of a $2 \mathrm{D}$ or $3 \mathrm{D}$ image on a screen might not be enough to achieve a more intuitive perception of complex anatomical details (Gerstle et al.). Its application and benefit in craniofacial and maxillofacial surgery has also been established, guaranteeing the reproducibility of the processes (Wagner et al.; Faber et al., 2006; Mavili et al., 2007; Elgalal et al.). The printing technique in surgery holds the potential of obtaining customized implants for patients with anatomical characteristics different from standard prostheses (D'Urso et al.; Rengier et al.); in this sense, procedures for maxillofacial reconstruction have already been successfully undertaken using artificial bone substitutes made by printing technology (Saijo et al., 2009). Within the framework of the stage in which virtual 3D models of MSs are produced, the present study was conducted through a manual limitation, which can have some drawbacks. Weissheimer et al. (2012) describe the manual technique as one in which the segmentation is done slide by slide, which is time-consuming and not practical in clinical conditions, and they defend the semiautomatic technique, which they characterize as significantly faster than the manual one. However, El \& Palomo (2010) established that the manual technique was the method with the greatest precision, giving the operator better control. The automatic segmentation is not done slide by slide, as in manual segmentation, and for that reason it does not allow all the irregular anatomical details to be specified, which can lead to errors (Alves et al., 2012).

There are factors that can affect manual limitation since it is based on the operator's ability to discriminate and the view is subject to the lighting conditions, fatigue, and ability to differentiate the gray scale (Weissheimer et al.). Nevertheless, the Slicer software has been used and described as sufficiently accurate for use in the creation of models (Szymor et al., 2016), so that the processes used in the present study are favorable. There has only been limited information reported in 3D printing of MSs, so that contrasting our analyses and result is difficult.
In relation to the MS and being an irregular 3D cavity, printing provided a better view of the anatomical details, which encourages their study. A physical model of the MS would help in the case of sinus lift surgeries, it could also serve to create customized implants to reconstitute a wall of the MS. It is important, however, to assess whether an accurate 3D prototype needs to be printed in every case, because the time for the slide-by-slide application is still considerable (Weissheimer et al.), particularly if a procedure must be performed quickly.

3D printing of the MS allows its real volume to be determined and compared with the volume calculated by software, which could also have forensic applications. From these initial data, new information can be analyzed in the future in relation to the MS.

Finally, we can conclude that the method for creating 3D models of MSs provides a new approach that makes it possible to appreciate precise anatomical characteristics in these structures, which cannot be assessed in the same way on a 2D screen. New studies are needed to determine the accuracy of the models with regard to surgical procedures or anthropological considerations in routine use in this area.

ARANEDA, N.; PARRA, M.; OSORIO, J. V.; OLATE, S. Impresión 3D del seno maxilar para su estudio morfológico. Int. J. Morphol., 35(3):1102-1106, 2017.

RESUMEN: El seno maxilar (SM) es una cavidad piramidal en maxila. El objetivo de este estudio es presentar una estrategia de análisis morfológico del SM utilizando impresión 3D a través de la adquisición de imágenes provenientes de tomografías computadorizadas cone beam (TCCB). Se realizó un estudio descriptivo transversal incluyendo 15 sujetos ( $8 \mathrm{mu}$ jeres y 7 hombres). Se realizó la reconstrucción y modelado virtual 3D de los SMs bilateralmente y se obtuvieron 30 modelos físicos generados en una impresora 3D. Los resultados arrojaron que los SMs obtenidos presentaban morfologías variadas, el análisis individual de cada SM permitió definir la condición tripoidal del SM, reparos anatómicos como el ostium del SM, mientras que zonas complejas relacionadas a decisiones quirúrgicas importantes pudieron ser observadas. Este método de creación de modelos 3D de SMs entrega un nuevo enfoque que permite apreciar características anatómicas precisas de estas estructuras, que no se pueden evaluar de la misma forma en una pantalla 2D. Se puede concluir que la impresión 3D de SM entrega un método de analisis prequirúrgico adecuado y que puede ser útil en la educación del paciente; otras estrategias con menor consumo de tiempo deben ser exploradas.

PALABRAS CLAVE: Seno maxilar; Impresión 3D; Biomodelo. 


\section{REFERENCES}

Alves, M. Jr.; Baratieri, C.; Mattos, C. T.; Brunetto, D.; Fontes, R. da D.; Santos, J. R. \& Ruellas, A. C. Is the airway volume being correctly analyzed? Am J. Orthod. Dentofacial Orthop., 141(5):657-61, 2012.

Amin, M. F. \& Hassan, E. I. Sex identification in Egyptian population using Multidetector Computed Tomography of the maxillary sinus. J. Forensic Leg. Med., 19(2):65-9, 2012.

D’Urso, P. S.; Barker, T. M.; Earwaker, W. J.; Bruce, L. J.; Atkinson, R. L.; Lanigan, M. W.; Arvier, J. F. \& Effeney, D. J. Stereolithographic biomodelling in cranio-maxillofacial surgery: a prospective trial. J. Craniomaxillofac. Surg., 27(1):30-7, 1999.

El, H. \& Palomo, J. M. Measuring the airway in 3 dimensions: a reliability and accuracy study. Am. J. Orthod. Dentofacial Orthop., 137(4):5-2, 2010.

Elgalal, M. T.; Kozakiewicz, M.; Olszycki, M.; Walkowiak, B. \& Stefanczyk, L. Custom implant design and surgical pre-planning using rapid prototyping and anatomical models for the repair of orbital floor fractures. Eur. Radiol., 19 Suppl. 1:S397, 2009.

Faber, J.; Berto, P. M. \& Quaresma, M. Rapid prototyping as a tool for diagnosis and treatment planning for maxillary canine impaction. Am. J. Orthod. Dentofacial Orthop., 129(4):583-9, 2006.

Gerstle, T. L.; Ibrahim, A. M.; Kim, P. S.; Lee, B. T. \& Lin, S. J. A plastic surgery application in evolution: three-dimensional printing. Plast. Reconstr. Surg., 133(2):446-51, 2014.

Holton, N.; Yokley, T. \& Butaric, L. The morphological interaction between the nasal cavity and maxillary sinuses in living humans. Anat. Rec. (Hoboken), 296(3):414-26, 2013.

Jun, B. C.; Song, S. W.; Park, C. S.; Lee, D. H.; Cho, K. J. \& Cho, $\mathrm{J}$. H. The analysis of maxillary sinus aeration according to aging process; volume assessment by 3-dimensional reconstruction by high-resolutional CT scanning. Otolaryngol. Head Neck Surg., 132(3):429-34, 2005.

Kirmeier, R.; Arnetzl, C.; Robl, T.; Payer, M.; Lorenzoni, M. \& Jakse, N. Reproducibility of volumetric measurements on maxillary sinuses. Int. J. Oral Maxillofac. Surg., 40(2):195-9, 2011.

Lawson, W.; Patel, Z. M. \& Lin, F. Y. The development and pathologic processes that influence maxillary sinus pneumatization. Anat. Rec. (Hoboken), 291(11):1554-63, 2008.

Matsumoto, K.; Ishiduka, T.; Yamada, H.; Yonehara, Y.; Arai, Y. \& Honda, K. Clinical use of three-dimensional models of the temporomandibular joint established by rapid prototyping based on cone-beam computed tomography imaging data. Oral Radiol., 30(1):98-104, 2014.

Mavili, M. E.; Canter, H. I.; Saglam-Aydinatay, B.; Kamaci, S. \& Kocadereli, I. Use of three-dimensional medical modeling methods for precise planning of orthognathic surgery. $J$. Craniofac. Surg., 18(4):740-7, 2007.

Misch, C. E.; Resnik, R. R. \& Misch-Dietsh, F. Maxillary Sinus Anatomy, Pathology, and Graft Surgery. In: Misch, C. E. (Ed.). Contemporary Implant Dentistry. 3rd ed. St. Louis, Mosby Elsevier, 2008.

Raghav, M.; Karjodkar, F. R.; Sontakke, S. \& Sansare, K. Prevalence of incidental maxillary sinus pathologies in dental patients on cone-beam computed tomographic images. Contemp. Clin. Dent., 5(3):361-5, 2014.

Rengier, F.; Mehndiratta, A.; von Tengg-Kobligk, H.; Zechmann, C. M.; Unterhinninghofen, R.; Kauczor, H. U. \& Giesel, F. L. $3 \mathrm{D}$ printing based on imaging data: review of medical applications. Int. J. Comput. Assist. Radiol. Surg., 5(4):335-41, 2010.

Saccucci, M.; Cipriani, F.; Carderi, S.; Di Carlo, G.; D’ Attilio, M.; Rodolfino, D.; Festa, F. \& Polimeni, A. Gender assessment through three-dimensional analysis of maxillary sinuses by means of cone beam computed tomography. Eur. Rev. Med. Pharmacol. Sci., 19(2):185-93, 2015.

Saijo, H.; Igawa, K.; Kanno, Y.; Mori, Y.; Kondo, K.; Shimizu, S.; Suzuki, S.; Chikazu, D.; Iino, M.; Anzai, M.; Sasaki, N.; Chung, U. I. \& Takato, T. Maxillofacial reconstruction using custommade artificial bones fabricated by inkjet printing technology. J. Artif. Organs, 12(3):200-5, 2009.

Szymor, P.; Kozakiewicz, M. \& Olszewski, R. Accuracy of opensource software segmentation and paper-based printed threedimensional models. J. Craniomaxillofac. Surg., 44(2):202-9, 2016.

Vidal, F. \& Vidal, R. Development of a novel protocol for digital implant planning using cone beam CTs, scanners and 3D printers: the full digital implant planning protocol. Clin. Oral Implants Res., 25( Suppl. 10):175, 2014.

Wagner, J. D.; Baack, B.; Brown, G. A. \& Kelly, J. Rapid 3-dimensional prototyping for surgical repair of maxillofacial fractures: a technical note. J. Oral Maxillofac. Surg., 62(7):898-901, 2004.

Weissheimer, A.; Menezes, L. M.; Sameshima, G. T.; Enciso, R.; Pham, J. \& Grauer, D. Imaging software accuracy for 3-dimensional analysis of the upper airway. Am. J. Orthod. Dentofacial. Orthop., 142(6):801-13, 2012.

Corresponding author:

Sergio Olate

Division of Oral and Maxillofacial Surgery

Claro Solar 115, Of. 414-A

Temuco

CHILE

E-mail: sergio.olate@ufrontera.cl

Received: 10-04-2017

Accepted: 24-07-2017 